and which is in use on the Tyne, consists of a series of belts or creepers and a continuous chain, with leaves attached, working in a trunk. The coal is lowered on to the belts, and is this conveyed any required horizontal distance until it reaches the end of the staith or pier against which the ship is moored. One end of the trunk, in - which the continunus chain or belt works, is lowered into the hold of the ship, and by means of the trays the coal is lowered down and gently deposited in the required position. The action of the lowering part of the apparatus is similar to that of a grain elevating machine, or of a bucket and ladder dredger; but of course the working is reversed, the material being lowered in place of being raised. The machine in use was said to be capable of dealing with 400 tons of coal an hour, and as, presumably, a machine could be used for each hatch, a vessel of say 2400 tons dead weight, and having three hatches could, we suppose, be brought to her bearings in a couple of hours. In the discussion that followed, the arrangement was rather sharply criticised, but it must be remembered that Cardiff is the home and birthplace of a rival scheme that has been in successful operation for some years. Naturally those who have used the older method and have experienced the benefit of it as compared with the primitive shoots, are loath to change, and it is also natural that the maker of the original apparatus should not welcome a competing scheme with too great enthusiasm. It would seem, however, that the Wrightson invention ought necessarily to have an advantage in point of speed because it is continuous, whilst the work with the older method is intermittent.

Mr. George B. Hammond's contribution, "On the Manufacture of Tin-plates," was an omnibus paper dealing with the subject at large--historically, commercially, and technically. From the historical and technical point of view, there was very little new to say, and indeed the commercial side of the question is already a thrice-told tale of sadness and decay. America was our great customer for tin-plates, and under the enormous impetus given to the industry by the spread of the canning trade in pro. visions fortunes were made in Sonth Wales, and enormous wages were paid. The inevitable reaction followed. The United States, pursuing their protectionist policy, put an import duty on tin-plates which was absolutely prohibitive, and that market was lost. There were, however, other outlets for the commodity, and had both employers and employed recognised the need of hard work and frugality the trade need never have fallen to the low ebb it has. Over-prosperity had, however, destroyed the moral fibre of those who had experienced it. There were large profits, high wages, antiquated methods, and artificial restrictions to output which no one wished to forego, and the consequence is that South Wales sees every prospect of American competition in neutral markets. This, however, is somewhat beside Mr. Hammond's paper; but it would be difficult for us to deal with the technical part without the illustrations of machinery which accompanied the paper.

On the following day, Wednesday, the first paper taken was that of Prof. Honoré Ponthière, "On a Thermo-chemical Study of the Refining of Iron." It was read in brief abstract by Mr. Brough in the absence of the author. From its title it will be seen how impossible it would be to abstract such a subject within anything approaching the limits of space at our disposal. It began with a discussion on the conditions under which the elements exist in iron, and treated of the various possible or probable reactions which take place during the process of steel-making by the two chief processes, and of puddling.

Mr. E. H. Saniter's paper "On Carbon and Iron" followed, being read in full by the author. This was the most important contribution to the meeting. It discussed the thermal treatment of tri-basic carbide of iron; the saturation point of iron with carbon by fusion in contact with excess of carbon; the saturation point of iron with carbon by heating without fusion in contact with excess of carbon; and the etching of pure carbon alloys at a red-heat in order to ascertain their structure by means of the microscope at that temperature. The last branch of the subject brought forward points of considerable interest, and the paper raised the old, and it would seem interminable, controversy on the alpha and beta states of iron. Mr. Saniter, we gather, is more of a carbonist than an allotropist, and his reasoning seemed to support the former party. Unfortunately there were no allotropists present, or if there were they were silent; so the discussion went all one way. The photo-micrographs attached to the paper were interesting, and in some respects this new method of treatment showed unexpected results. Mr. Saniter made a strange mistake in his paper. He attributed to sn competent an authority as Edward Riley the statement that the saturationpoint of iron for carbon was 4 per cent. Mr. Riley, who was present, naturally exclaimed against this, and asked Mr. Saniter for his authority, which the latter gave as the Journal of the Institute for the year 1877 . What the saturation-point may be has not, we believe, been exactly determined, but at any rate it is higher than 4 per cent. Mr. Saniter's mistake, of course, was that he did not verify his authority when the statement was so questionable and the reference to the original so easy.

The last paper read at the meeting was Mr. Henning's contribution on a recorder of stretching, which was taken charge of by Mr. Wicksteed, in the ausence of the author. The portable recorder referred to consists of a pair of clamps attached to the two ends of the specimen rod. To one of these clamps is attached a parallel motion with a projecting arm, at the end of which is a pencil. The motion is worked by rod from the other clamp, so that when the specimen stretches, and the clamps are thus pulled apart, the arm moves. In this way a record can be obtained on a card which is mounted on a revolving drum, which is actuated by a cord from the poise weight. It will be seen that in construction the apparatus bears a resemblance to a steam engine indicator, both in regard to the parallel motion and the paper-drum. It was objected during the discussion that the poise could not be moved fast enough to give true indications when the specimen ultimately gave way; but probably if a recrord can be obtained within the elastic limit, that will be sufficient for the majority of engineers, as a material strained beyond this limit is very little good for structural purposes.

Five other papers were on the agenda, but were not read at the meeting.

The excursions and entertainments during this meeting were numerous and the hospitality profuse. Several of the large iron and steel works were visited, the Cardiff and Newport docks were inspected, and also other places of industrial interest. There were lunches, dinners, soirées, a Welsh concert, garien parties, and illuminations packed in as close as time would permit ; but the culminating point in all these delights was the Marchioness of Bute's ball. To this over three thousand guests, including all the members of the Iron and Steel Institute and the ladies accompanying them, were invited.

\section{ON PRACTICALLY AVAILABLE PROCESSES FOR SOLDERING ALUMINIUM IN THE LABORATORY.}

I $\mathrm{T}$ seems that ever since the metal aluminium has been used in construction, difficulties have arisen in soldering it. Further, from contemporary literature it appears probable that some perfectly satisfactory methods of getting over the difficulty are known, but not published in sufficient detail to be available.

Hence it seems well to put on record any advance towards the solution of this somewhat troublesome problem. In the first place, my experience is that it is not easy to solder aluminium simply by using an alloy of definite composition without a flux. Also that the only other process which does not require special apparatus, that based upon the use of silver chloride, is very troublesome indeed unless the local fusion of the aluminium be immaterial. I find, however, that cadmium iodide is distinctly more satisfactory. If it be fused on an aluminium plate, decomposition of the salt occurs long before the melting point of the aluminium is reached. The result is generally the violent evolution of iodine vapour and formation of an alloy of cadmium and aluminium on the surface of the metal.

The decomposition of the cadmium iodide is, however, too rapid to be convenient, and the pulverulent white residue is in the way. It is, therefore, of advantage to add some other body which, if possible, will obviate these defects. I find that zinc chloride answers fairly well. Thus I mix concentrated zinc chloride solution with a little ammonium chloride, evaporate in a round porcelain dish, and ignite a low red heat till a part of the ammonium chloride is volatilised. The fused chlorides are now mixed with cadmium iodide. The proportions of zinc chloride and cadmium iodide are best adjusted experimentally.

The final result, when the salts are completely fused together, is a flux which readily enables tin (or other soldering alloy) to unite perfectly with aluminium. The melted flux can be taken up in a pipette with india-rubber teat, and dropped on to the surface of the metal to be soldered. Some powdered metallic 
tin is also sprinkled on the surface. The aluminium is then heated over the Bunsen flame till the flux just melts ; it can then be quickly spread where it is wanted with a piece of copper wire or thin glass rod. As the temperature is further raised the flux decomposes, and the tin readily alloys itself with the surtace of the aluminiun ; while the flux is decomposing, the tin can be spread in a continuous layer by means of the little glass rod or wire.

Instead of cadmium iodide, fused lead chloride may be used in a similar manner.

I should like to substitute some of the less volatile alkylammonium chlorides for the ammonium chloride, but have not had opportunity.

A. T. Stanton.

\section{THE STUDY OF NATURAL HISTORY IN $J A P A N$.}

A NEW publication, entitled Annotationes Zoologicae Japonenses, has just been launched at Tokyo, under the auspices of the Zoological Society there. In 1888 the Society commenced the issue of a monthly journal--the Döbutsugakr Zasshi (Zoological Magazine)-in the Japanese language, and the periodical is now in its ninth volume. About two years ago a department written in European languages was added to the magazine, and the new publication may be regarded as another step forward in the same direction. The old and the new magazines will be carried on as separate publications; but while the former will be exclusively intended for Japanese students, the latter will be issued primarily for the purpose of making the progress of zoology in Japan better known outside that country. For the present, the Annotationes will be published quarterly, and the intention is to widely distribute it among all institutions and societies interested in zoological progress. In the future, therefore, zoologists may chiefly look for contributions to their branch of science from Japanese sources in two publications, viz. in the Journal of the College of Science, Imperial University, for elaborate memoirs, and in the new periodical for shorter notices and papers. Other publications, such as the Bulletin of the College of Agriculture, will, of course, occasionally publish articles on zoological subjects as heretofore.

In introducing the new journal, and defining its aim and scope, Dr. K. Mitsukuri, Professor of Zoology in the Imperial University, and President of the Tokyo Zoological Society, gives a brief retrospect, which is abridged below, of the progress of zoology in Japan.

It is probably unknown to most persons in the West that early in the eighth century of the Christian era there was already established in Japan an Imperial University with four departments-Ethics, History, Jurisprudence, and Mathematics -and with the prescribed number of four hundred students. There were also, at the same time, a bureau devoted to Astronomy, Astrology, Calendar-compilation and Meteorology, and a Medical College with professors of Medicine, Surgery, Acupuncture, Necromancy (the art of healing by charms), and Pharmacology. The last-named branch of study included the collection, cultivation, and investigation of medicinal plants, and thus a considerable amount of botanical knowledge must already have been acquired by that time. Towards the end of the ninth century, when a catalogue of books existing in Japan was compiled by the order of the then reigning Emperor, the Imperial library was found to contain 16,790 volumes, divided into forty departments-and this in spite of a disastrous fire of some years previous. Among the medical works were some with very modern sounding titles, such as "The Curing of Diseases of Women," and "On the Methods of Healing Diseases of the Horse." Japan in those early days derived its culture from India, China, and Korea; but the details above enumerated clearly show that educated society must already have attained a high degree of civilisation.

Coming to more modern times, it is known that, during the long peace of two hundred and fifty years which the rule of the Tokugawa shoguns secured for Japan, literature, the arts, and all peaceful industries were developed with remarkable vigour and rapidity, and that the study of natural history shared in this progress. Apart from that innate love of nature and the natural which was ever showing itself in poetry and other arts, the study of natural products was always pursued, ostensibly with the purpose of collecting materia medica, or of discovering things that might be used as food in case of a famine, or of identifying objects mentioned in the Confucian classic, "ShiKing." But it is not difficult to perceive that naturalists looked in reality beyond these simple or utilitarian ends, and investigated animals and plants for their own sake, although the principal aim of their researches seems to have been the comparatively barren one of establishing a relationship between Japanese products and those described in various Chinese works on natural history. Frequent were the excursions and expeditions undertaken with the view of collecting natural objects, among which plants were especial favourites, and all parts of the country seem to have been tolerably well explored in this way. Numerous were the treatises on natural history, published or unpublished. Many of these were encyclopædic in their comprehensiveness and size, such as "Shobutsu Ruisan," by Inao Jakusui (1000 parts, early in the eighteenth century), and "Honzō Kōmoku Keimō," by Ono Ranzan (48 parts, I803). The last-named naturalist was so famous for his extensive knowledge that, we are told, his pupils were nearly one thousand in number. Prof. Matsumura, in his book on the enumeration of Japanese plant-names, gives 306 titles of Japanese works on botany compiled previously to I868. Many of the natural history volumes had beautiful coloured illus. trations, which serve their purpose even at the present day. natural history displays were of common occurrence, when naturalists came together with their treasures, and showed them to one another and to the public. Of these the exhibitions given by Hiraga Gennai in the middle of the eighteenth century were perhaps the most celebrated. The present Botanic Garden of the Imperial University was established early in the Tokugawa period, viz. in $\mathrm{I} 68 \mathrm{I}$, and was long renowned as the "O Yaku En" (Garden of Medicinal Plants). The mastery of the Dutch language by a few earnest physicians in the middle of the eighteenth century is one of the greatest triumphs ever achieved by patient scholarship. Originally undertaken with the purpose of ascertaining something about Western medicine, their efforts soon exerted an influence on all branches of learning. The whole rich treasury of Western civilisation became suddenly accessible through the channel thus opened of the Dutch language. It is not possible to over-estimate the effect of the new acquisition on the progress of Japan. Suffice it to say that the country would not be what it is to-day but for this leaven which had been working through and through the whole mass of society for over a hundred years before the Restoration of 1868 enabled it to bear its legitimate fruit. This innovation, together with the visits of Thunberg (1775) and Siebold (I82I), had due effect upon the natural history studies also. The system of Linné, especially in regard to plants, seems to have been well grasped, with very little delay. The most famous productions of the new school on natural history subjects are probably "Shokugaku Keigen" (Elements of Botanical Science) by Udagawa Yoan, 1835; and "Sömoku Zusetsu" (Icones Plantarum) by Iinuma Yokusai, I832-the latter being a standard work at the present day. It is perhaps a circumstance interesting enough to record that a work on the use of the microscope was published in I80I.

Looked at from the modern standpoint, the natural history of the pre-Restoration period (before I868) was without doubt strongest in botany. The science of zoology seems to have been greatly backward in its development compared with that of the sister science, and its study was probably sinilar in method and aim to that of the Middle Ages in Europe. It seems to have concerned itself mostly with making commentaries on Chinese works of natural history, like "Honzō Kömoku," or with identifying Japanese objects with names given in those writings. Excepting a little on birds, fishes and shells, hardly any work that can be called scientific, in any modern sense, seems to have been accomplished. Nevertheless this schonl did an immense service by showing that the study of natural objects was worth the best efforts of intellectual men. Names like Arai Hakuseki, Inao Jakusui, Kaibara Ekken, Ono Ranzan, ${ }^{1}$ are among the most honoured in the annals of our learning.

With the restoration of the Emperor to his full power, in I868, came the wholesale reconstruction of all political institutions, and the country has been, and is still, going through such a social revolution as has seldom been witnessed in any part of the world. Along with many other things, the old school of 1 All these names are given in the Japanese fashion, with the surname
first. 